\title{
Correlation analysis of expression and prognosis of TTF-1 and CD44v6 in undifferentiated lung carcinoma
}

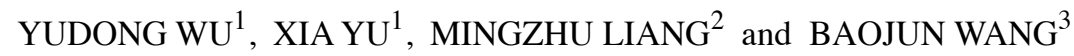 \\ ${ }^{1}$ Department of Respiration, Penglai Traditional Chinese Medicine Hospital; \\ ${ }^{2}$ Department of Surgery, Penglai People's Hospital, Yantai, Shandong 265600; \\ ${ }^{3}$ Department of Oncology, Baiyin Central Hospital, Baiyin, Gansu 730913, P.R. China
}

Received March 11, 2019; Accepted July 4, 2019

DOI: $10.3892 / \mathrm{ol} .2019 .10689$

\begin{abstract}
The correlation between expression and prognosis of thyroid transcription factor-1 (TTF-1) and CD44v6 in undifferentiated lung carcinoma was investigated. There were 116 cases with large cell undifferentiated carcinoma in group A, 120 cases with small cell undifferentiated carcinoma in group B and 80 normal individuals from the same period in group $\mathrm{C}$. The expression levels of TTF-1 and CD44v6 in the serum of group $\mathrm{A}, \mathrm{B}$ and $\mathrm{C}$ and the cancer tissues and adjacent tissues of group $\mathrm{A}, \mathrm{B}$ and $\mathrm{C}$ were detected using enzyme-linked immunosorbent assay (ELISA), and the levels in each group were compared. Pearson's test was used to analyze the correlation between TTF-1 and CD44v6 expression in serum of group A and group B and cancer tissues. Patients were divided into the survival group and the deceased group according to their 5-year survival. Multivariate logistic regression was applied to analyze the risk factors of mortality, and receiver operating characteristic curve (ROC) was used to analyze the diagnostic value of TTF-1 and CD44v6. The best cut-off values of TTF-1 and CD44v6 were divided into the high and low expression groups to observe the 5-year mortality of patients and the Kaplan-Meier (K-M) survival curve was drawn. Multivariate logistic regression was used to analyze the risk factors of mortality. The expression of CD44v6 in the serum of group A and group B was higher than that in group $\mathrm{C}$, and that of group $\mathrm{B}$ was higher than that in group A $(\mathrm{P}<0.05)$. The expression of TTF-1 in serum of group A and group B was higher than that of group C, and the expression of TTF-1 in group A was higher than that in group $\mathrm{B}(\mathrm{P}<0.05)$. The expression of TTF-1 and CD44v6 in group A and group B were significantly higher than those in
\end{abstract}

Correspondence to: Dr Baojun Wang, Department of Oncology, Baiyin Central Hospital, 13 Baoji Road, Baiyin, Gansu 730913, P.R. China

E-mail: bbkwn0@163.com;jmwbj_ok@126.com

Key words: TTF-1, CD44v6, undifferentiated lung carcinoma, large cell undifferentiated carcinoma, small cell undifferentiated carcinoma adjacent tissues $(\mathrm{P}<0.05)$. The expression of TTF-1 in group A was higher than that in group $\mathrm{B}(\mathrm{P}<0.05)$, and that of $\mathrm{CD} 44 \mathrm{v} 6$ was lower than that in group $\mathrm{B}(\mathrm{P}<0.05)$. The 5-year survival of patients showed that 209 patients died and 27 survived at 5 years; the survival rate was $11.44 \%$. The course of disease, TNM stage, TTF-1 and CD44v6 were independent mortality factors for undifferentiated lung cancer.

\section{Introduction}

Lung cancer is the main cause of cancer-related mortality among males in developed and less developed countries (1) and is one of the malignant tumors that pose a great threat to human health. Especially with the increase of smoking, obesity and physical inactivity, the incidence rate of some low molecular lung cancer is increasing, and the incidence rate and mortality rate of lung cancer are on the rise (2). The obscure symptoms in its early stage are often misdiagnosed as other respiratory diseases, resulting in a more serious condition when diagnosed. Undifferentiated lung carcinoma, a common type of lung cancer with poor differentiation of tumor cells, can be divided into small cell undifferentiated carcinoma and large cell undifferentiated carcinoma according to the histological morphology of tumor cells. Small cell undifferentiated carcinoma (small cell cancer) is the most malignant cancer, accounting for $\sim 13-15 \%$ of the total lung cancer (3), which mainly occurs in the large bronchus near the segmental bronchus, with its cancer cells having the characteristics of fast growth, rapid development, strong invasiveness, and easy migration to the brain, liver, adrenal gland, and bone. It is sensitive to radiotherapy and chemotherapy, but with a poor prognosis (4). Whereas large cell undifferentiated carcinoma (large cell cancer) has larger cancer cells, lower incidence, higher malignant degree and poorer prognosis (5).

It has been found that thyroid transcription factor-1 (TTF-1), as a member of $\mathrm{NK} \times 2$ family of nucleoprotein transcription factors in the same region, plays a crucial role in lung development, cell growth and differentiation, and is one of the suppressor genes of lung adenocarcinoma. As a highly sensitive and specific molecular marker of lung adenocarcinoma, TTF-1 can help to differentiate lung adenocarcinoma $(6,7)$. Hara et al (8) considered that TTF-1 was a favorable prognostic factor for lung adenocarcinoma. Matzke-Ogi et al (9) also considered that TTF-1 was overexpressed in $95 \%$ of primary 
lung adenocarcinoma, but TTF-1 was also a favorable prognostic factor for non-phosphorous non-small cell lung cancer patients. Although more attention has been paid to the study of TTF-1 in lung cancer in recent years, there are few studies on the expression and prognosis of TTF-1 in undifferentiated lung cancer. CD44, located in the short arm of chromosome 11, is mainly involved in heterotypic adhesion (10), that is, the adhesion of tumor cells to host cells and host mechanisms, and promotes the invasion and metastasis of tumor cells (11). CD44v6, a member of CD44 family having a close relationship with tumor cell invasion and metastasis (12), has been found to play an important role in the occurrence, metastasis and prognosis of various malignant tumors in recent years (13-15). Matzke-Ogi et al (9) found that elevated levels of CD44v6 in patients with metastatic pancreatic tumors were associated with shorter survival time. However, we still do not know the expression and prognosis of CD44v6 and TTF-1 in undifferentiated lung cancer.

The present study explored the correlation between expression and prognosis of TTF-1 and CD44v6 in undifferentiated lung cancer to provide reference and direction for clinical practice.

\section{Patients and methods}

General data. One hundred and sixteen patients with large cell cancer admitted to Penglai Traditional Chinese Medicine Hospital (Yantai, China), from June 2011 to February 2013 were collected as group A, 120 cases with small cell cancer as group B, and 80 normal individuals as group $\mathrm{C}$. There were 66 males and 50 females in group A aged from 44 to 75 $(61.5 \pm 10.4)$ years, 71 males and 49 females in group B aged from 43 to 78 years $(62.1 \pm 10.6), 46$ males and 34 females in group $\mathrm{C}$ aged from 45 to 78 years $(61.8 \pm 10.6)$. This study was approved by the Medical Ethics Committee of Penglai Traditional Chinese Medicine Hospital and the patients were informed. Signed informed consents were obtained from the patients or their guardians. Inclusion criteria: i) The patients were pathologically diagnosed with undifferentiated lung cancer; ii) no radiotherapy or chemotherapy was performed before the surgery; iii) the clinical data were complete and the patients could be followed up by telephone. Exclusion criteria: i) Patients with suspicious pathology and mixed pathology; ii) patients with serious heart and lung function diseases and other diseases; iii) pregnant or lactating women.

Reagents and instruments. CD44v6 protein ELISA test kit (Shanghai J\&l Biotechnology Co., Ltd., JL19068); TTF-1 ELISA test kit (Shanghai LMAI Biology Co., Ltd., LM-TTF1-Hu).

Detection method. Five milliliters of sterile venous blood was collected at 7 a.m. the day after admission, and serum was immediately separated by centrifugation at 3,000 $\mathrm{x}$ g for $15 \mathrm{~min}$ at $4^{\circ} \mathrm{C}$, and anticoagulated with ethylenediaminetetraacetic acid (EDTA), and stored at $-80^{\circ} \mathrm{C}$, and cancer tissues and adjacent tissues were collected from group A and group B. Concentration of the standard: TTF-1 dilution concentration: 8, 4, 2, 1 and $0.5 \mathrm{ng} / \mathrm{ml}$; CD44v6 dilution concentration: 80 , 40, 20, 10 and $5 \mathrm{ng} / \mathrm{ml}$. Blank, standard and testing sample wells were set. Fifty microliters of standard with different concentrations was added to the standard wells, $50 \mu 1$ of testing sample to the testing sample wells, and $100 \mu 1$ of enzyme labeled antibody to all the wells. Then the reaction wells were sealed with a closure plate membrane, incubated for $60 \mathrm{~min}$ at $37^{\circ} \mathrm{C}$ in a water bath or constant temperature box. Next, the liquid was discarded and dried with absorbent paper, and the washing buffer $(350 \mu \mathrm{l})$ was added to each well for $1 \mathrm{~min}$, then discarded and dried with absorbent paper. The plate was washed five times. Afterwards, $50 \mu \mathrm{l}$ of each substrate A and $\mathrm{B}$ was added to each well, and incubated at $37^{\circ} \mathrm{C}$ in the dark for $15 \mathrm{~min}$. Fifty microliters of stop solution was added to each well, then the optical density (OD) value was measured at $450 \mathrm{~nm}$ wavelength within $15 \mathrm{~min}$. A standard curve was drawn and a linear regression equation was obtained, and the OD value of the sample was substituted into the equation to calculate the concentration of the sample.

Outcome measures. Main outcome measures: The expression of TTF-1 and CD44v6 in the serum of groups A, B and C and the tissues of group A and group B were compared. The patients were followed up by telephone at 1, 3, 6, 12, 24, 36, 48 and 60 months after admission to record their 5-year survival and to divide them into the survival group and the deceased group. Then the expression of TTF-1 and CD44v6 in the two groups was compared and the mortality risk factors were analyzed by multivariate logistic regression.

Secondary outcome measures: Receiver operating characteristic (ROC) curve was used to analyze the diagnostic value of TTF-1 and CD44v6 and the best cut-off value in undifferentiated cancer mortality. The patients were divided into the high and low expression groups according to the values in order to observe the 5-year mortality and the Kaplan-Meier (K-M) survival curve was drawn.

Statistical analysis. SPSS 20.0 (Shanghai Cabit Information Technology Co., Ltd.) medical statistical analysis software was used to carry out statistical analysis on the collected data. GraphPad Prism 7 (Shenzhen Soft Head Technology Co., Ltd.) was used to draw figures. The enumeration data expressed as a rate $(\%)$ were analyzed using the Chi-squared test (denoted by $\chi^{2}$ ). The Kolmogorov-Smirnov (K-S) test was used to analyze the data distribution, and the measurement data were expressed as the mean \pm standard deviation (mean \pm SD). The independent samples t-test was used for comparison of the normal distribution data between two groups (denoted by t), and one-way analysis of variance (ANOVA) was used for the comparison between multiple groups (denoted by F). LSD-t test was the post hoc test. Rank sum test was used for ranked data. Pearson's test was used to analyze the correlation between TTF-1 and CD44v6 expression in serum of group A and group B and cancer tissues. ROC was used for evaluation of the ability of TTF-1 and CD44v6 to diagnose undifferentiated cancer and mortality; K-M was used for 5-year survival analysis with log rank test, and Logistic regression analysis for multivariate analysis. $\mathrm{P}<0.05$ was regarded as statistically significant.

\section{Results}

Basic information and clinical data of patients. Basic information and clinical data were compared in the three 
Table I. Clinical data of patients.

\begin{tabular}{|c|c|c|c|c|c|}
\hline Factors & Group A $(n=116)$ & Group B $(n=120)$ & Group C $(\mathrm{n}=80)$ & $\mathrm{t} / \chi^{2} / \mathrm{F} / \mathrm{Z}$ & P-value \\
\hline \multicolumn{6}{|l|}{ Sex } \\
\hline Male & $66(56.90)$ & $71(59.17)$ & $46(57.50)$ & \multirow[t]{2}{*}{1.647} & \multirow[t]{2}{*}{0.329} \\
\hline Female & $50(43.10)$ & $49(40.83)$ & $34(42.50)$ & & \\
\hline Age (years) & $61.5 \pm 10.4$ & $62.1 \pm 10.6$ & $62.8 \pm 10.6$ & 0.363 & 0.696 \\
\hline Course of disease (years) & $3.52 \pm 1.64$ & $3.21 \pm 1.34$ & & 1.545 & 0.124 \\
\hline BMI $\left(\mathrm{kg} / \mathrm{m}^{2}\right)$ & $21.15 \pm 3.18$ & $22.08 \pm 3.47$ & $21.93 \pm 3.25$ & 2.585 & 0.077 \\
\hline \multicolumn{6}{|l|}{ Smoking history } \\
\hline Yes & $43(37.07)$ & $48(40.00)$ & $27(33.75)$ & \multirow[t]{2}{*}{0.677} & \multirow[t]{2}{*}{0.572} \\
\hline No & $73(62.93)$ & $72(60.00)$ & $53(66.25)$ & & \\
\hline \multicolumn{6}{|l|}{ History of alcohol abuse } \\
\hline Yes & $25(21.55)$ & $24(20.00)$ & $11(13.75)$ & \multirow[t]{2}{*}{0.113} & \multirow[t]{2}{*}{0.897} \\
\hline No & $91(78.45)$ & $96(80.00)$ & $69(86.25)$ & & \\
\hline \multicolumn{6}{|l|}{ Residence } \\
\hline Urban & $84(66.67)$ & $87(71.43)$ & $60(75.00)$ & \multirow[t]{2}{*}{0.202} & \multirow[t]{2}{*}{0.828} \\
\hline Rural & $32(33.33)$ & $33(28.57)$ & $20(25.00)$ & & \\
\hline \multicolumn{6}{|l|}{ TNM stage } \\
\hline I & $19(16.38)$ & $21(17.50)$ & & \multirow{4}{*}{0.215} & \multirow{4}{*}{0.829} \\
\hline II & $42(25.86)$ & $44(25.84)$ & & & \\
\hline III & $50(34.48)$ & $49(33.33)$ & & & \\
\hline IV & $5(4.32)$ & $6(5.00)$ & & & \\
\hline \multicolumn{6}{|l|}{ Distal metastasis } \\
\hline Yes & 48 & 51 & & \multirow[t]{2}{*}{0.030} & \multirow[t]{2}{*}{0.862} \\
\hline No & 68 & 69 & & & \\
\hline
\end{tabular}

BMI, body mass index; TNM stage, TNM tumor staging system.

Table II. TTF-1 and CD44v6 expression in groups A, B and C.

\begin{tabular}{|c|c|c|c|c|c|}
\hline Groups & Group A $(n=116)$ & Group B $(n=120)$ & Group C $(n=80)$ & $\mathrm{t}$ value & P-value \\
\hline TTF-1 (ng/ml) & $157.34 \pm 45.91$ & $110.79 \pm 21.35^{\mathrm{a}}$ & $93.18 \pm 11.23^{\mathrm{a}, \mathrm{b}}$ & 312.93 & $<0.001$ \\
\hline CD44v6 (ng/ml) & $154.28 \pm 40.17$ & $196.44 \pm 59.10^{\mathrm{a}}$ & $112.31 \pm 25.27^{\mathrm{a}, \mathrm{b}}$ & 96.59 & $<0.001$ \\
\hline
\end{tabular}

${ }^{\mathrm{a}}<0.05$, compared with group $\mathrm{A}$; ${ }^{\mathrm{b}} \mathrm{P}<0.05$, compared with group $\mathrm{B}$. TTF-1, thyroid transcription factor- 1 .

groups.There were 116 patients in group A, 66 males and 50 females, with an average age of $61.5 \pm 10.4$ years, an average disease course of $3.52 \pm 1.64$ years, an average body mass index (BMI) of $21.15 \pm 3.18 \mathrm{~kg} / \mathrm{m}^{2}, 43$ with smoking history, 25 with history of alcohol abuse, 84 urban residents and 32 rural residents. Whereas, there were 120 patients in group B, 71 males and 49 females, with an average age of $62.1 \pm 10.6$ years, an average disease course of $3.21 \pm 1.34$ years, an average BMI of $22.08 \pm 3.47 \mathrm{~kg} / \mathrm{m}^{2}$, 48 with smoking history, 24 with history of alcohol abuse, 87 urban residents and 33 rural residents. Group $C$ consisted of 80 individuals, 46 males and 34 females with an average age of $61.8 \pm 10.6$ years, an average BMI of $21.93 \pm 3.25 \mathrm{~kg} / \mathrm{m}^{2}$, 27 with smoking history, 11 with history of alcohol abuse, 60 urban residents and 20 rural residents. There was no statistical difference in clinical data between the two groups (P>0.05) (Table I).

Expression of TTF-1 and CD44v6 in the serum of groups $A$, $B$ and $C$ and the tissues of groups $A$ and $B$. The results of enzyme linked immunosorbent assay (ELISA) showed that the expression of CD44v6 in the serum of group A and group B was higher than that in group $\mathrm{C}$, and the expression in group $\mathrm{B}$ was higher than that in group $\mathrm{A}(\mathrm{P}<0.05)$. TTF-1 expression in group A and group B was higher than that in group $\mathrm{C}$, and the expression in group $\mathrm{A}$ was higher than that in group $\mathrm{B}$ $(\mathrm{P}<0.05)$ (Table II). The expression of TTF-1 and CD44v6 in group A and group B was significantly higher than those in adjacent tissues $(\mathrm{P}<0.05)$ (Tables III and IV). The expression of TTF-1 in group A was significantly higher than that in group B 
Table III. Expression of TTF-1 and CD44v6 in group A and adjacent tissues.

\begin{tabular}{lccrr}
\hline Group A & Cancer tissue $(\mathrm{n}=116)$ & Paracancerous tissue $(\mathrm{n}=116)$ & $\mathrm{t}$ value & P-value \\
\hline TTF-1 $(\mathrm{ng} / \mathrm{ml})$ & $159.07 \pm 45.37$ & $96.24 \pm 10.32$ & 13.495 & $<0.001$ \\
CD44v6 $(\mathrm{ng} / \mathrm{ml})$ & $153.54 \pm 39.84$ & $114.25 \pm 23.45$ & 9.166 & $<0.001$ \\
\hline
\end{tabular}

TTF-1, thyroid transcription factor-1.

Table IV. Expression of TTF-1 and CD44v6 in group B and adjacent tissues.

\begin{tabular}{lccrr}
\hline Group B & Cancer tissue $(\mathrm{n}=120)$ & Paracancerous tissue $(\mathrm{n}=120)$ & $\mathrm{t}$ value & P-value \\
\hline TTF-1 $(\mathrm{ng} / \mathrm{ml})$ & $112.95 \pm 21.24$ & $93.18 \pm 11.23$ & 9.883 & $<0.001$ \\
CD44v6 $(\mathrm{ng} / \mathrm{ml})$ & $196.43 \pm 56.10$ & $112.31 \pm 25.27$ & 14.254 & $<0.001$ \\
\hline
\end{tabular}

TTF-1, thyroid transcription factor-1.

Table V. Comparison of TTF-1 and CD44v6 expression in groups A and B cancer tissues.

\begin{tabular}{lcccr}
\hline Cancer tissues & Group A $(\mathrm{n}=116)$ & Group B $(\mathrm{n}=120)$ & t value & P-value \\
\hline TTF-1 $(\mathrm{ng} / \mathrm{ml})$ & $159.07 \pm 45.37$ & $112.95 \pm 21.24$ & 8.189 & $<0.001$ \\
CD44v6 $(\mathrm{ng} / \mathrm{ml})$ & $153.54 \pm 39.84$ & $196.43 \pm 56.10$ & 5.808 & $<0.001$ \\
\hline
\end{tabular}

TTF-1, thyroid transcription factor- 1 .
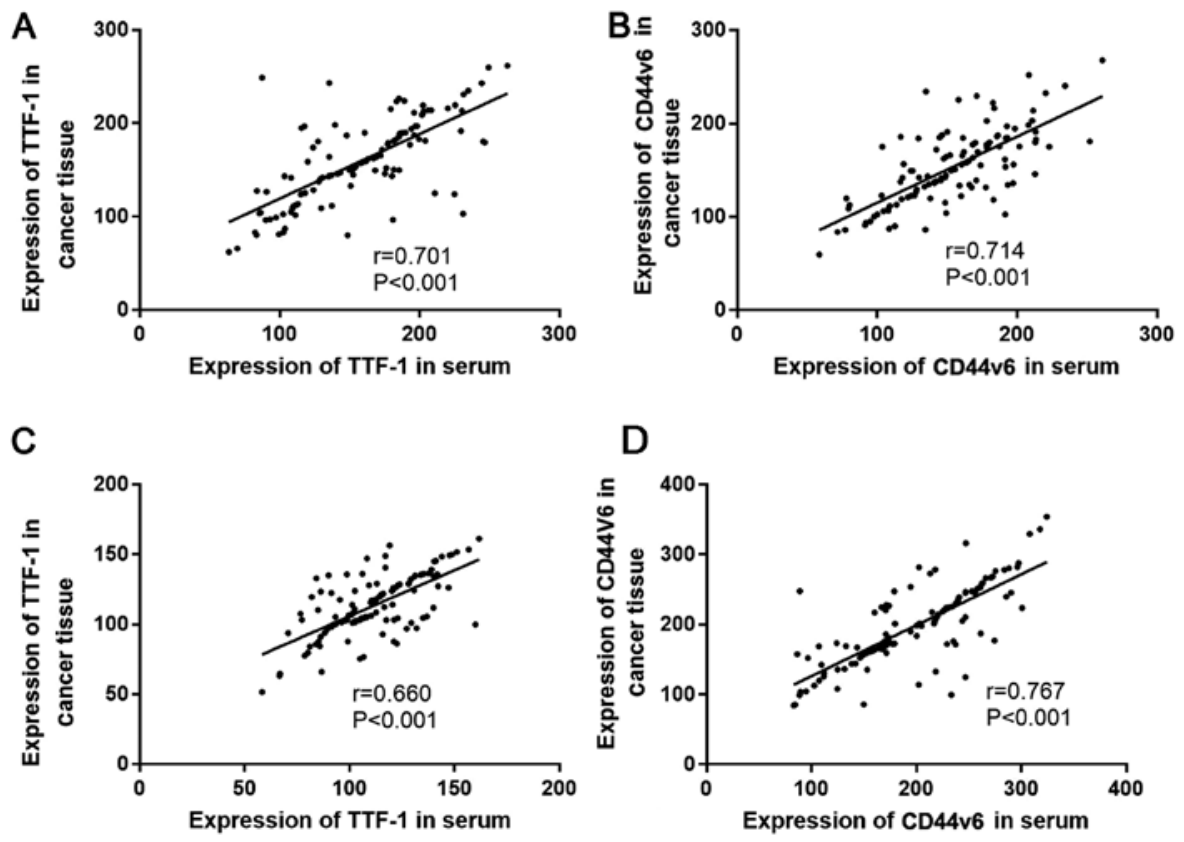

Figure 1. Correlation between the expression of TTF-1 and CD44v6 in serum of group A and group B and cancer tissues. (A) The expression of TTF-1 in serum of group A was positively correlated with the expression of TTF-1 in cancer tissues ( $\mathrm{r}=0.701, \mathrm{P}<0.001)$. (B) The expression of CD44v6 in serum of group A was positively correlated with the expression of $\mathrm{CD} 44 \mathrm{v} 6$ in cancer tissues $(\mathrm{r}=0.714, \mathrm{P}<0.001)$. (C) The expression of TTF-1 in serum of group B was positively correlated with the expression of TTF-1 in cancer tissues $(\mathrm{r}=0.660, \mathrm{P}<0.001)$. (D) The expression of $\mathrm{CD} 44 \mathrm{v} 6$ in serum of group B was positively correlated with the expression of CD44v6 in cancer tissues $(\mathrm{r}=0.767, \mathrm{P}<0.001)$.

$(\mathrm{P}<0.05)$, and the expression of CD44v6 was significantly lower than that in group $\mathrm{B}(\mathrm{P}<0.05)$, as shown in Table $\mathrm{V}$.
Correlation between the expression of TTF-1 and CD44v6 in serum of groups $A$ and $B$ and cancer tissues. Pearson's 
Table VI. ROC curve data.

\begin{tabular}{lccccrr}
\hline Indexes & AUC & $95 \%$ CI & Specificity & Sensitivity & Youden index & Cut-off \\
\hline TTF-1 & 0.852 & $0.812-0.893$ & $68.64 \%$ & $98.75 \%$ & $67.39 \%$ & $<112.981$ \\
CD44v6 & 0.840 & $0.797-0.883$ & $67.37 \%$ & $88.75 \%$ & $56.12 \%$ & $<144.333$ \\
Joint detection & 0.934 & $0.908-0.960$ & $81.70 \%$ & $96.25 \%$ & $79.55 \%$ & $<0.228$
\end{tabular}

AUC, area under curve; cut-off, cut-off point; 95\% CI, confidence interval. TTF-1, thyroid transcription factor-1.

Table VII. ROC curve data.

\begin{tabular}{|c|c|c|c|c|c|c|}
\hline Indexes & AUC & $95 \% \mathrm{CI}$ & Specificity & Sensitivity & Youden index & Cut-off \\
\hline TTF-1 & 0.766 & $0.702-0.831$ & $60.34 \%$ & $91.67 \%$ & $52.01 \%$ & $<147.148$ \\
\hline CD44v6 & 0.715 & $0.649-0.780$ & $83.62 \%$ & $52.50 \%$ & $36.12 \%$ & $<197.000$ \\
\hline Joint detection & 0.820 & $0.766-0.875$ & $73.28 \%$ & $80.00 \%$ & $53.28 \%$ & $<0.502$ \\
\hline
\end{tabular}

AUC, area under curve; cut-off, cut-off point; 95\% CI, confidence interval. TTF-1, thyroid transcription factor-1.

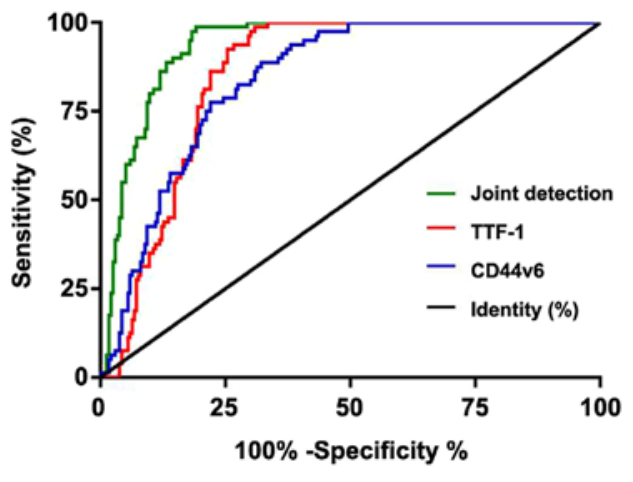

Figure 2. ROC curve of TTF-1 and CD44v6 in diagnosis of undifferentiated lung cancer. TTF-1 AUC was $0.852,95 \%$ CI, $0.812-0.893$; CD44v6 AUC was $0.840,95 \%$ CI, $0.797-0.883$, and the combined detection of AUC was 0.934 , 95\% CI, 0.908-0.960.

correlation analysis showed that TTF-1 expression was positively correlated with TTF-1 expression in cancer tissues $(\mathrm{r}=0.701, \mathrm{P}<0.001)$, and $\mathrm{CD} 44 \mathrm{v} 6$ expression in serum was positively correlated with $\mathrm{CD} 44 \mathrm{v} 6$ expression in cancer tissues $(\mathrm{r}=0.714, \mathrm{P}<0.001)$. The expression of TTF-1 in serum of group B was positively correlated with the expression of TTF-1 in cancer tissues $(r=0.660, \mathrm{P}<0.001)$. The expression of CD44v6 in serum was positively correlated with the expression of CD44v6 in cancer tissues $(r=0.767$, $\mathrm{P}<0.001)$ (Fig. 1).

Diagnostic value of TTF-1 and CD44v6 in undifferentiated cancer. ROC curve of the expression of TTF-1 and CD44v6 in the serum of three groups of patients was plotted in order to analyze their diagnostic value in undifferentiated cancer. The results showed that the area under curve (AUC) and $95 \%$ confidence interval (CI) of TTF-1 were 0.852 and $0.812-0.893$, respectively; those of CD44v6 were 0.840 and 0.797-0.883; and those of joint detection were 0.934 and 0.908-0.960, respectively (Table VI and Fig. 2).

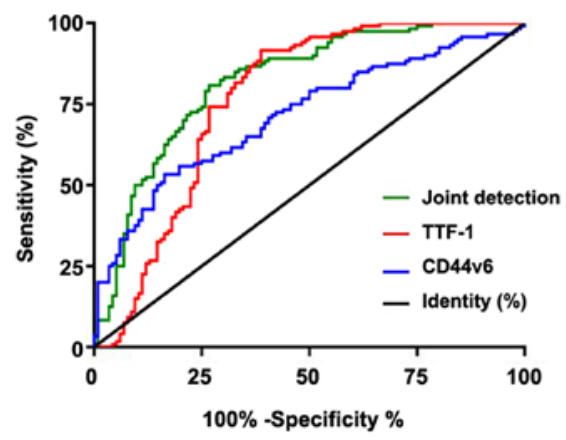

Figure 3. ROC curves of TTF-1 and CD44v6 in the diagnosis of large and small cell cancers. TTF-1 AUC was $0.766,95 \%$ CI, 0.702-0.831; CD44v6 AUC was $0.715,95 \%$ CI, 0.649-0.780, and combined detection AUC was 0.820, 95\% CI, 0.766-0.875.

Diagnostic value of TTF-1 and CD44v6 in large and small cell cancers. ROC curve analysis of TTF- 1 and CD44v6 expression in group A and group B was plotted to analyze their diagnostic value in large and small cell cancers. The results showed that AUC and 95\% CI of TTF-1 were 0.766 and $0.702-0.831$, respectively; those of CD44v6 were 0.715 and $0.649-0.780$, and those of joint detection curve were 0.820 and 0.766-0.875, respectively (Table VII and Fig. 3).

Survival of patients. The 5-year survival of patients in group A and group B were recorded. All the patients $(n=236)$ were followed up successfully, 209 died and 27 survived at 5 years, with a survival rate of $11.44 \%$ (Fig. 4).

Expression of TTF-1 and CD44v6 in deceased and survival groups. The patients were divided into the survival group $(n=27)$ and the deceased group $(n=209)$ according to the 5-year survival of patients in group A and group B. ELISA showed that the expression of TTF- 1 and CD44v6 in the serum of the deceased group were higher than that in the survival group $(\mathrm{P}<0.05)$, as shown in Table VIII. 
Table VIII. Expression of TTF-1 and CD44v6 in mortality and survival groups.

\begin{tabular}{|c|c|c|c|c|}
\hline Groups & Deceased group $(n=209)$ & Survival group $(n=27)$ & $\mathrm{t}$ value & P-value \\
\hline TTF-1 (ng/ml) & $182.96 \pm 51.27$ & $121.04 \pm 27.67$ & 6.153 & $<0.001$ \\
\hline CD44v6 (ng/ml) & $197.04 \pm 60.22$ & $144.34 \pm 51.88$ & 4.342 & $<0.001$ \\
\hline
\end{tabular}

TTF-1, thyroid transcription factor- 1 .

Table IX. Diagnostic value of TTF-1 and CD44v6 in undifferentiated lung cancer mortality.

\begin{tabular}{|c|c|c|c|c|c|c|}
\hline Indexes & AUC & $95 \%$ CI & Specificity & Sensitivity & Youden index & Cut-off \\
\hline TTF-1 & 0.866 & $0.820-0.912$ & $66.99 \%$ & $100.00 \%$ & $66.99 \%$ & $<163.312$ \\
\hline CD44v6 & 0.746 & $0.684-0.808$ & $46.41 \%$ & $92.56 \%$ & $38.97 \%$ & $<199.417$ \\
\hline Joint detection & 0.897 & $0.857-0.936$ & $75.60 \%$ & $92.59 \%$ & $68.19 \%$ & $<0.914$ \\
\hline
\end{tabular}

AUC, area under curve; cut-off, cut-off point; 95\% CI, confidence interval. TTF-1, thyroid transcription factor-1.

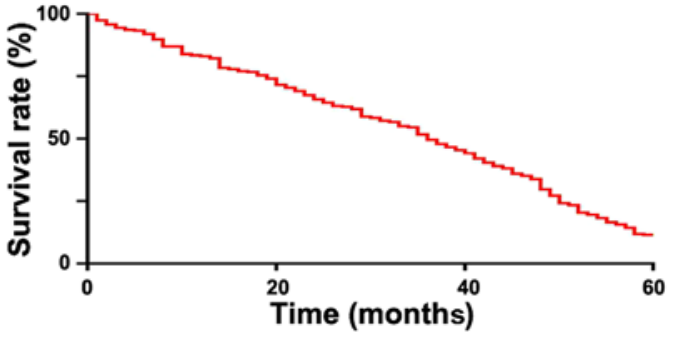

Figure 4. Five-year survival of patients. The 5-year survival rate was $11.44 \%$.

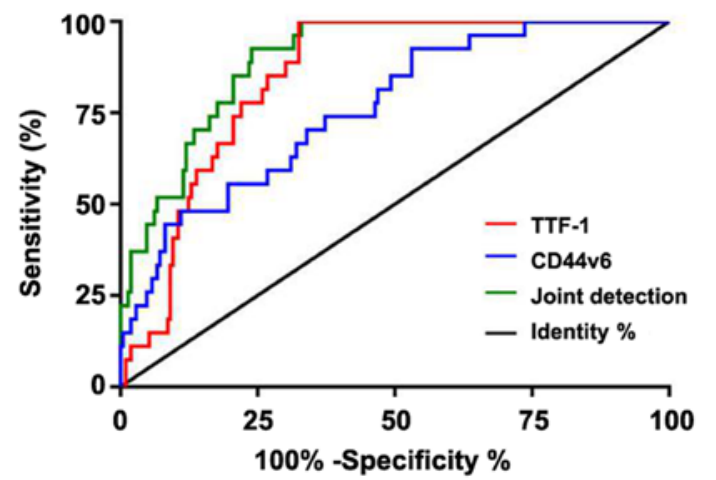

Figure 5. ROC curve of TTF-1 and CD44v6 in undifferentiated lung cancer mortality. TTF-1 AUC was 0.866, 95\% CI, 0.820-0.912; CD44v6 AUC was $0.746,95 \%$ CI, 0.684-0.808, and the combined detection of AUC was 0.897, $95 \%$ CI, 0.857-0.936.

Diagnostic value of TTF-1 and CD44v6 in undifferentiated lung cancer mortality. ROC curve of the expression of TTF-1 and CD44v6 in surviving and non-survivng patients was plotted to analyze their diagnostic value in undifferentiated lung cancer. The results showed that the AUC and 95\% CI of TTF-1 were 0.866 and $0.820-0.912$, respectively, those of CD44v6 were 0.746 and $0.684-0.808$, and those of the joint detection were 0.897 and $0.857-0.936$, respectively (Table IX and Fig. 5).

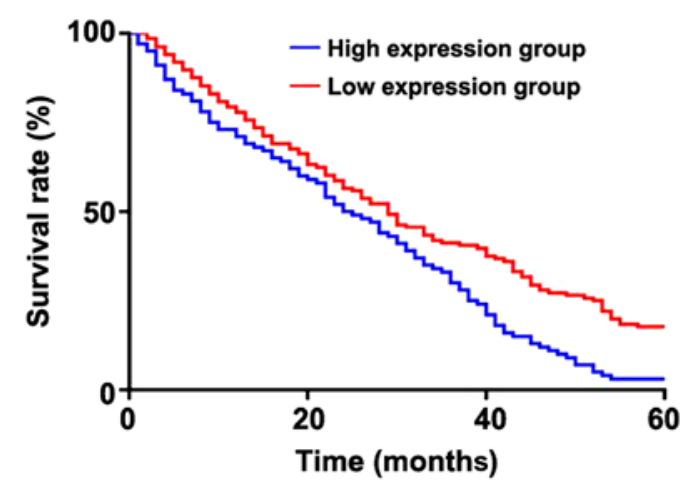

Figure 6. Correlation between TTF-1 expression and 5-year survival of patients. The 5-year survival of patients with high TTF-1 expression was significantly lower than that of patients with low TTF-1 expression $(\mathrm{P}<0.001)$.

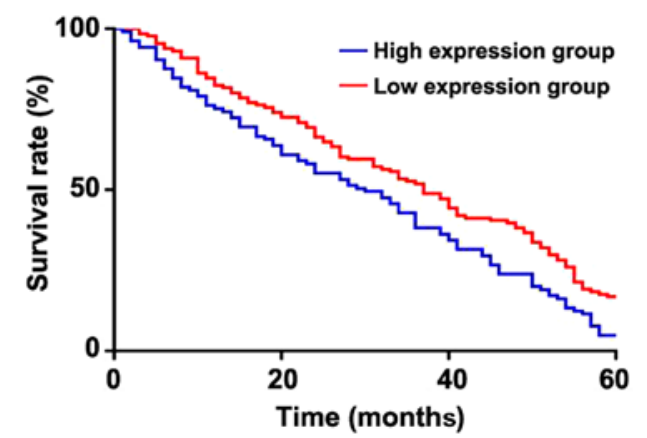

Figure 7. Correlation between CD44v6 expression and 5-year survival of patients. The 5-year survival of the high-expression group was significantly lower than that of the low-expression group $(\mathrm{P}=0.0041)$.

Correlation between the expression of TTF-1 and CD44v6 and the 5-year survival of patients. The patients were divided into high and low expression groups according to the cut-off points of expression of TTF-1 and CD44v6 in undifferentiated lung cancer mortality. The K-M survival curve found that the survival in TTF-1 high expression group was significantly 
Table X. Univariate analysis.

\begin{tabular}{|c|c|c|c|c|}
\hline Factor & Deceased group $(n=209)$ & Survival group $(n=27)$ & $\mathrm{t} / \chi^{2} / \mathrm{Z}$ & P-value \\
\hline \multicolumn{5}{|l|}{ Sex } \\
\hline Male & $119(66.51)$ & $18(66.67)$ & 0.929 & 0.335 \\
\hline Female & $90(33.49)$ & $9(33.33)$ & & \\
\hline Age (years) & $60.7 \pm 10.2$ & $61.2 \pm 10.5$ & 0.239 & 0.811 \\
\hline Course of disease (year) & $3.79 \pm 2.03$ & $2.67 \pm 1.82$ & 2.728 & 0.007 \\
\hline BMI $\left(\mathrm{kg} / \mathrm{m}^{2}\right)$ & $23.55 \pm 1.34$ & $23.06 \pm 1.90$ & 1.695 & 0.091 \\
\hline \multicolumn{5}{|l|}{ Smoking history } \\
\hline Yes & $87(41.63)$ & $4(14.81)$ & 7.256 & 0.007 \\
\hline No & $122(58.37)$ & $23(85.19)$ & & \\
\hline \multicolumn{5}{|l|}{ History of alcohol abuse } \\
\hline Yes & $41(19.62)$ & $8(29.63)$ & 1.457 & 0.227 \\
\hline No & $168(80.38)$ & $19(70.37)$ & & \\
\hline \multicolumn{5}{|l|}{ Residence } \\
\hline Urban & $151(72.25)$ & $20(74.07)$ & 0.040 & 0.842 \\
\hline Rural & $58(27.75)$ & $7(25.93)$ & & \\
\hline \multicolumn{5}{|l|}{ TNM stage } \\
\hline I & $33(15.79)$ & $7(25.93)$ & & \\
\hline II & $73(34.93)$ & $13(48.14)$ & 2.368 & 0.018 \\
\hline III & $92(44.02)$ & $7(25.93)$ & & \\
\hline IV & $11(5.26)$ & $0(0)$ & & \\
\hline \multicolumn{5}{|l|}{ TTF-1 } \\
\hline$<161.900$ & $113(54.07)$ & $23(85.19)$ & 9.482 & 0.002 \\
\hline$\geq 161.900$ & $96(45.93)$ & $4(14.81)$ & & \\
\hline \multicolumn{5}{|l|}{ CD44v6 } \\
\hline$<185.600$ & $116(55.50)$ & $22(81.48)$ & 6.646 & 0.010 \\
\hline$\geq 185.600$ & $93(44.50)$ & $5(18.52)$ & & \\
\hline \multicolumn{5}{|l|}{ Distal metastasis } \\
\hline Yes & $92(44.02)$ & $7(25.93)$ & 3.867 & 0.049 \\
\hline No & $117(55.98)$ & $20(74.07)$ & & \\
\hline
\end{tabular}

BMI, body mass index; TNM stage, TNM tumor staging system; TTF-1, thyroid transcription factor-1.

Table XI. Assignment table.

\begin{tabular}{lc}
\hline Factors & Assignment \\
\hline Course of disease & $\geq 2$ years $=1,<2$ years $=0$ \\
Smoking history & Yes $=1$, No=0 \\
TNM stage & III, IV $=1 ; \mathrm{I}, \mathrm{II}=0$ \\
Distal metastasis & Yes $=1, \mathrm{No}=0$ \\
TTF-1 & $<163.312=1, \geq 163.312=0$ \\
CD44v6 & $<199.417=1, \geq 199.417=0$ \\
Mortality status & Deceased $=1$, Survival $=0$
\end{tabular}

TNM stage, TNM tumor staging system; TTF-1, thyroid transcription factor-1.

lower than that in the low expression group $(\mathrm{P}=0.0005)$, and the survival in the CD44v6 high expression group was significantly lower than that in the low expression group $(\mathrm{P}=0.0041)$ (Figs. 6 and 7).

Univariate analysis of survival. The clinical data of patients in the deceased and survival groups were collected for univariate analysis. It was found that there was no difference in sex, BMI, age, history of alcohol abuse and residence between the two groups $(\mathrm{P}>0.05)$. However, there was statistical difference in the course of disease, smoking history or TNM stage $(\mathrm{P}<0.05)$ (Table $\mathrm{X})$.

Multivariate analysis of survival. The indicators with differences in univariate analysis were included into an assignment (Table XI). Then a multivariate logistic regression analysis (forward: LR) was carried out and showed that smoking history and distal metastasis were not independent risk factors of undifferentiated lung cancer mortality during the course of disease (OR, 0.349; 95\% CI, 0.160-0.761), TNM stage (OR, 3.183; 95\% CI, 1.514-6.695), TTF-1 (OR, 0.110; 95\% CI, 0.050-0.242) and CD44v6 (OR, 0.262; 95\% CI, 0.124-0.552) (Table XII). 
Table XII. Multivariate analysis of survival.

95\% CI of EXP (B)

\begin{tabular}{lccccccc}
\cline { 5 - 8 } Factors & $\mathrm{B}$ & $\mathrm{SE}$ & Wald & Sig. & Exp (B) & Lower limit & Upper limit \\
\hline Course of disease & -1.053 & 0.398 & 7.012 & 0.008 & 0.349 & 0.160 & 0.761 \\
TNM stage & 1.158 & 0.379 & 9.319 & 0.002 & 3.183 & 1.514 & 6.695 \\
TTF-1 & -2.208 & 0.403 & 29.956 & $<0.01$ & 0.110 & 0.050 & 0.242 \\
CD44v6 & -1.340 & 0.381 & 12.38 & $<0.01$ & 0.262 & 0.124 & 0.552 \\
\hline
\end{tabular}

B, constant term; SE, standard deviation; Wald, Chi-square value; sig., P-value; Exp (B), odds ratio; 95\% CI of Exp (B), $95 \%$ confidence interval of odds ratio. TTF-1, thyroid transcription factor-1.

\section{Discussion}

Lung cancer is the leading cause of cancer mortality for human worldwide. The lack of specific and sensitive tools for early diagnosis and the inadequacy of targeted treatment have resulted in unsatisfactory treatment results (16). The cause is still unclear, but study has shown that environmental pollution and long-term smoking are closely related to the occurrence of lung cancer (17). Undifferentiated lung cancer, characterized by poor differentiation of tumor cells, high degree of malignancy, strong invasion and poor prognosis, is divided into large cell cancer and small cell cancer according to the histological morphology of tumor cells. TTF-1 plays an important role in the differentiation of lung epithelial cells in the early stage (18), and is also crucial to the formation and structure of lung tissue. Ma et al (19) has found that TTF-1 expression in lung squamous cell carcinoma and lung adenocarcinoma is increased, but the specific mechanism of the increase is still unclear. Moreover, there are few studies on the correlation between expression and prognosis of TTF-1 in undifferentiated lung cancer. CD44 is an important cell surface adhesion molecule and is closely related to the invasion and metastasis of tumor cells. Studies have shown that the abnormal expression of CD44v6, a member of the CD44 family, has a close relationship with the occurrence, development, metastasis and prognosis of various tumor cells $(9,20-22)$. Some scholars found that the activity of CD44/CD44v6 depends on the connection with integral membrane and cytosolic signaling molecules, protease and transcriptional regulation (23), thus promoting tumor metastasis. However, it is still unclear whether CD44v6 can be used as a prognostic indicator for undifferentiated lung cancer.

In this study, we collected large differentiated cancer patients, small differentiated cancer patients and normal individuals. The expression of TTF- 1 and CD44v6 in the serum of the three groups and patient tissues were detected by ELISA. It was found that the expression of TTF-1 and CD44v6 in the serum of undifferentiated cancer patients were higher than that in normal individuals, and the expression of TTF- 1 and CD44v6 in cancer tissues was also higher than that in adjacent tissues. This is similar to the results by Perner et al (24) which showed TTF-1 was highly expressed in various lung cancer types, and also to the study by Tran et al (25) which suggested CD44v6 was highly expressed in squamous cell carcinoma. The expression of TTF-1 in large cell cancer patients was higher than that in small cell cancer patients, but the expression of CD44v6 was the opposite, with statistical differences, which indicates that TTF-1 and CD44v6 may be potential diagnostic indicators of undifferentiated cancer. In this study, it was found that the AUC of TTF- 1 and CD44v6 was 0.852 and 0.840 , respectively through the ROC curve for diagnosis of undifferentiated cancer. The joint curve of TTF-1 and CD44v6 was plotted, and the AUC was 0.934. When the cut-off point was less than 0.228 , the optimal specificity and sensitivity were 81.70 and $96.25 \%$, which were significantly better than the single detection. This study also found that the AUC of TTF- 1 and CD44v6 was 0.766 and 0.715 through ROC curve for diagnosis of large and small cell cancers. The AUC of the joint curve was 0.820 . When the cut-off point was less than 0.502 , the optimal specificity and sensitivity were 81.70 and $96.25 \%$, and the diagnosis of large and small cell cancers was also higher than that of single detection. Therefore, the expression of TTF-1 and CD44v6 can be diagnostic indicators of large and small cell cancers.

A follow-up survey was conducted on the survival of patients in group A and group B. In total 236 patients were followed up, 209 died and 27 survived at 5 years, with a survival rate of $11.44 \%$. The patients were divided into groups according to their mortality conditions, and the diagnostic value of TTF-1 and CD44v6 in undifferentiated lung cancer mortality was predicted by ROC curve. AUC of TTF-1 was 0.848 , and when the cutoff point was less than 163.312 the optimal specificity and sensitivity were 66.99 and $100.00 \%$; the AUC of CD44v6 was 0.762 , when the cutoff point was less than 199.417 the optimal specificity and sensitivity were 46.41 and $92.56 \%$, respectively. Thus, the sensitivity and specificity of the two indicators were quite different when they were detected separately. Therefore, joint detection was carried out with an AUC of 0.897, and when the cutoff point was less than 0.914 , the optimal specificity and sensitivity were 75.60 and $92.59 \%$, respectively, indicating that joint detection can make up the defects between the two factors. The patients were divided into high and low expression groups according to the cut-off points of TTF- 1 and CD44v6, and the K-M survival curve was plotted. It was found that the patients with high expression of TTF-1 and CD44v6 had significantly lower 5-year survival than the patients with low expression, similar to the result of Situ et al (26) that the survival rate of patients with high expression of CD44v6 in non-small cell cancer patients is lower than that of patients with low expression. Shinohara et al (27) also reported that the 5-year survival 
rate of CD44v6 overexpression in cancer tissues was lower by immunohistochemistry and that the prognosis of CD44v6 overexpression in serum by ELISA was worse, which further confirmed our view. This study also found that low expression of TTF-1 and CD44v6 were protective factors for patients' mortality through multivariate logistic regression analysis, which suggested that the expression of TTF-1 and CD44v6 can be used as predictors of 5-year mortality of patients with undifferentiated lung cancer, and the course of disease and TNM stage of patients were independent risk factors of undifferentiated lung cancer mortality.

However, there are some limitations in this study. Correlation between TTF-1 and CD44v6 was not analyzed and the specific mechanism of TTF-1 and CD44v6 on the growth, proliferation and invasion of tumor cells was not studied. Therefore, the relationship between TTF-1 and CD44v6 and the occurrence mechanism need to be explored in later studies to verify the results of the present study.

In conclusion, the course of disease, TNM stage, TTF-1 and CD44v6 are independent mortality factors of undifferentiated lung cancer patients. TTF-1 and CD44v6 have certain diagnostic value in undifferentiated lung cancer and can be used as mortality predictors of undifferentiated lung cancer.

\section{Acknowledgements}

Not applicable.

\section{Funding}

No funding was received.

\section{Availability of data and materials}

The datasets used and/or analyzed during the present study are available from the corresponding author on reasonable request.

\section{Authors' contributions}

YW wrote the manuscript and was also involved in the design and conception of the study. XY was responsible for ELISA. ML analyzed and interpreted the patients' data. BW helped with statistical analysis. All authors read and approved the final manuscript.

\section{Ethics approval and consent to participate}

The study was approved by the Medical Ethics Committee of Penglai Traditional Chinese Medicine Hospital (Yantai, China). Patients, who participated in this research, had complete clinical data. Signed informed consents were obtained from the patients or their guardians.

\section{Patient consent for publication}

Not applicable.

\section{Competing interests}

The authors declare that they have no competing interests.

\section{References}

1. Torre LA, Bray F, Siegel RL, Ferlay J, Lortet-Tieulent J and Jemal A: Global cancer statistics, 2012. CA Cancer J Clin 65: 87-108, 2015.

2. Aristarco V, Serrano D, Gandini S, Johansson H, Macis D, Guerrieri-Gonzaga A, Lazzeroni M, Feroce I, Pruneri G, Pagani G, et al: A randomized, placebo-controlled, phase II, presurgical biomarker trial of celecoxib versus exemestane in postmenopausal breast cancer patients. Cancer Prev Res (Phila) 9: 349-356, 2016.

3. Alvarado-Luna G and Morales-Espinosa D: Treatment for small cell lung cancer, where are we now? - a review. Transl Lung Cancer Res 5: 26-38, 2016.

4. Rudin CM, Ismaila N, Hann CL, Malhotra N, Movsas B, Norris K, Pietanza MC, Ramalingam SS, Turrisi AT III and Giaccone G: Treatment of small-cell lung cancer: American Society of Clinical Oncology Endorsement of the American College of Chest Physicians Guideline. J Clin Oncol 33: 4106-4111, 2015.

5. Hanagiri T, Oka S, Takenaka S, Baba T, Yasuda M, Ono K, So T, Uramoto H, Takenoyama M and Yasumoto K: Results of surgical resection for patients with large cell carcinoma of the lung. Int $\mathrm{J}$ Surg 8: 391-394, 2010.

6. Sumi T, Hirai S, Yamaguchi M, Tanaka Y, Tada M, Yamada G, Hasegawa T, Miyagi Y, Niki T, Watanabe A, et al: Survivin knockdown induces senescence in TTF 1-expressing, KRAS-mutant lung adenocarcinomas. Int J Oncol 53: 33-46, 2018.

7. Puglisi F, Aprile G, Bruckbauer M, Barbone F, Damante G, Guerra S, Beltrami CA and Di Loreto C: Combined analysis of MIB-1 and thyroid transcription factor-1 predicts survival in non-small cell lung carcinomas. Cancer Lett 162: 97-103, 2001.

8. Hara K, Saito T, Hayashi T, Mitani K, Takamochi K, Oh S, Suzuki K and Yao T: Inverse correlation between galectin-4 and TTF-1 in lung adenocarcinoma. Virchows Arch 471: 375-382, 2017.

9. Matzke-Ogi A, Jannasch K, Shatirishvili M, Fuchs B, Chiblak S, Morton J, Tawk B, Lindner T, Sansom O, Alves F, et al: Inhibition of tumor growth and metastasis in pancreatic cancer models by interference with CD44v6 signaling. Gastroenterology 150 : 513-525.e10, 2016.

10. Ssadh HA, Spencer PS, Alabdulmenaim W, Alghamdi R, Madar IH, Miranda-Sayago JM and Fernández N: Measurements of heterotypic associations between cluster of differentiation CD74 and CD44 in human breast cancer-derived cells. Oncotarget 8: 92143-92156, 2017.

11. Okayama H, Kumamoto K, Saitou K, Hayase S, Kofunato Y, Sato Y, Miyamoto K, Nakamura I, Ohki S, Sekikawa K, et al: CD44v6, MMP-7 and nuclear Cdx2 are significant biomarkers for prediction of lymph node metastasis in primary gastric cancer. Oncol Rep 22: 745-755, 2009.

12. Ekici S, Cerwinka WH, Duncan R, Gomez P, Civantos F, Soloway MS and Lokeshwar VB: Comparison of the prognostic potential of hyaluronic acid, hyaluronidase (HYAL-1), CD44v6 and microvessel density for prostate cancer. Int J Cancer 112: 121-129, 2004.

13. Chen JQ, Zhan WH, He YL, Peng JS, Wang JP, Cai SR and Ma JP: Expression of heparanase gene, CD44v6, MMP-7 and nm23 protein and their relationship with the invasion and metastasis of gastric carcinomas. World J Gastroenterol 10: 776-782, 2004.

14. Liu YJ, Yan PS, Li J and Jia JF: Expression and significance of CD44s, CD44v6, and nm23 mRNA in human cancer. World $\mathrm{J}$ Gastroenterol 11: 6601-6606, 2005.

15. Wang Z, von Au A, Schnölzer M, Hackert T and Zöller M: CD44v6-competent tumor exosomes promote motility, invasion and cancer-initiating cell marker expression in pancreatic and colorectal cancer cells. Oncotarget 7: 55409-55436, 2016.

16. Ferlay J, Soerjomataram I, Dikshit R, Eser S, Mathers C, Rebelo M, Parkin DM, Forman D and Bray F: Cancer incidence and mortality worldwide: Sources, methods and major patterns in GLOBOCAN 2012. Int J Cancer 136: E359-E386, 2015.

17. Hori M, Tanaka H, Wakai K, Sasazuki S and Katanoda K: Secondhand smoke exposure and risk of lung cancer in Japan: A systematic review and meta-analysis of epidemiologic studies. Jpn J Clin Oncol 46: 942-951, 2016.

18. Tanaka Y, Yamaguchi M, Hirai S, Sumi T, Tada M, Saito A, Chiba H, Kojima T, Watanabe A, Takahashi $\mathrm{H}$, et al: Characterization of distal airway stem-like cells expressing $\mathrm{N}$-terminally truncated p63 and thyroid transcription factor- 1 in the human lung. Exp Cell Res 372: 141-149, 2018. 
19. Ma Y, Fan M, Dai L, Kang X, Liu Y, Sun Y, Yan W, Liang Z, Xiong $\mathrm{H}$ and Chen $\mathrm{K}$ : The expression of TTF-1 and Napsin A in early-stage lung adenocarcinoma correlates with the results of surgical treatment. Tumour Biol 36: 8085-8092, 2015.

20. Yu Q and Stamenkovic I: Localization of matrix metalloproteinase 9 to the cell surface provides a mechanism for CD44-mediated tumor invasion. Genes Dev 13: 35-48, 1999.

21. Amirghofran Z, Jalali SA, Hosseini SV, Vasei M, Sabayan B and Ghaderi A: Evaluation of CD44 and CD44v6 in colorectal carcinoma patients: Soluble forms in relation to tumor tissue expression and metastasis. J Gastrointest Cancer 39: 73-78, 2008.

22. Marzese DM, Liu M, Huynh JL, Hirose H, Donovan NC, Huynh KT, Kiyohara E, Chong K, Cheng D, Tanaka R, et al: Brain metastasis is predetermined in early stages of cutaneous melanoma by CD44v6 expression through epigenetic regulation of the spliceosome. Pigment Cell Melanoma Res 28: 82-93, 2015.

23. Wang Z, Zhao K, Hackert T and Zöller M: CD44/CD44v6 a reliable companion in cancer-initiating cell maintenance and tumor progression. Front Cell Dev Biol 6: 97, 2018.

24. Perner S, Wagner PL, Soltermann A, LaFargue C, Tischler V, Weir BA, Weder W, Meyerson M, Giordano TJ, Moch H, et al: TTF1 expression in non-small cell lung carcinoma: Association with TTF1 gene amplification and improved survival. J Pathol 217: 65-72, 2009.
25. Tran TA, Kallakury BV, Sheehan CE and Ross JS: Expression of CD44 standard form and variant isoforms in non-small cell lung carcinomas. Hum Pathol 28: 809-814, 1997.

26. Situ D, Long H, Lin P, Zhu Z, Wang J, Zhang X, Xie Z and Rong T: Expression and prognostic relevance of CD44v6 in stage I non-small cell lung carcinoma. J Cancer Res Clin Oncol 136: 1213-1219, 2010.

27. Shinohara S, Hanagiri T, Taira A, Takenaka M,Oka S, Chikaishi Y Uramoto H, So T, Yamada S and Tanaka F: Immunohistochemical expression and serum levels of CD44 as prognostic indicators in patients with non-small cell lung cancer. Oncology 90: 327-338, 2016.

This work is licensed under a Creative Commons Attribution-NonCommercial-NoDerivatives 4.0 International (CC BY-NC-ND 4.0) License. 